\title{
MINIMISASI WASTE PADA RADIOGRAPHY TEST PROYEK PERLUASAN KILANG MINYAK PT. PERTAMINA CILACAP MENGGUNAKAN METODE DMAIC
}

\author{
Victorianus Iva Taufik dan Sawarni Hasibuan \\ Program Studi Magister Teknik Industri Universitas Mercu Buana Jakarta \\ e-mail: sawarni@mercubuana.ac.id
}

\begin{abstract}
ABSTRAK
PT. Sucofindo merupakan salah satu perusahaan yang memiliki izin untuk memanfaatkan bahan radioaktif untuk uji radiografi dalam rangka mendukung pembangunan kilang minyak di proyek Cilacap. Permasalahan yang dihadapi oleh perusahaan adalah hasil tes pengulangan tinggi yang mencapai 8\%. Tujuan dari penelitian ini adalah untuk mengurangi pengulangan tes menggunakan metode DMAIC. Pada tahap awal dicoba mengidentifikasi akar penyebab rework yang terjadi selama pengujian dengan Fishbone diagram dan melakukan analisis dari diagram tersebut. Berdasarkan studi, penyebab utama dari masalah yang disebabkan oleh pengulangan rekayasa, pemrosesan film, dan penanganan. Fokus pada masalah utama dengan menggunakan Force Field Analysis (FFA) melakukan penelitian tentang penyebab masalah untuk menentukan usulan perbaikan yang mungkin dari permasalahan yang ada. Proposal alternatif yang dibuat dengan menggunakan FFA, melalui pelatihan dan menyegarkan tentu saja dengan melibatkan para ahli, ada penurunan tingkat kerja pengulangan tes yang dilakukan selama uji pengamatan 3 bulan. Hasil pengujian pengulangan turun dari 8\% menjadi 4,21\%. Komitmen dan keterlibatan perusahaan manajemen merupakan faktor kunci. Untuk menjaga skor setelah analisis, monitoring dan kontrol dilakukan oleh audit manajemen
\end{abstract}

Kata kunci: Radiografi Test, Limbah / Mengolah / mensyuting ulang, DMAIC, Field Analysis Paksa

\begin{abstract}
PT. Sucofindo is one company that is authorized to utilize radioactive material for radiographic test in order to support the construction of an oil refinery in Cilacap project. Problems faced by the company are the high repeatability test results which reached $8 \%$. The purpose of this research is to reduce the repetition of tests using the DMAIC method. In the early stages docoba identified the root causes of rework that occurs during the test with Fish Bone tools and Why-why analysis. Based on the study the main cause of the problems caused by the repetition of engineering, film processing, and handling. Focus on the main problems with using a Force Field Analysis (FFA) conducts research on the causes of the problem to determine the proposed improvements are possible from the existing problems. The alternative proposals made by using FFA, through training and refreshing course with the involvement of experts, there is a decrease in the employment rate of repetition of the tests performed during the observation test 3 months. The result of testing repeatability down from $8 \%$ to $4.21 \%$. The commitment and involvement of management companies is a key factor. To keep the score after the analysis, monitoring and control is carried out by the management audit
\end{abstract}

Keywords: Radiography Test, Waste/Rework/Reshoot, DMAIC, Forced Field Analysis

\section{PENDAHULUAN}

Untuk memenuhi kebutuhan BBM dan menekan impor, pemerintah telah melakukan perluasan infrastruktur beberapa kilang minyak. Salah satu proyek perluasan kilang milik Pertamina dengan nama Residual Fluid Catalytic Cracking (RFCC) dibangun di Cilacap. Proyek ini diharapkan mampu memproduksi produk gasoline sebesar 2 juta kiloliter untuk memasok 34 persen kebutuhan BBM nasional atau 60 persen kebutuhan BBM di Pulau Jawa. Dalam perluasan kilang minyak tersebut diperlukan pemastian terhadap kualitas pengelasan pada pipa-pipa minyak. PT Sucofindo termasuk salah satu perusahaan yang diberi izin oleh BAPETEN (Badan Pengawas Tenaga Nulkir) untuk memanfaatkan zat radioactive berupa Iridium-192 dalam uji radiography pada sambungan las yang ada dalam proyek tersebut. Peranan PT. Sucofindo dalam melakukan uji radiography dalam proyek tersebut menjadi penting, karena menjadi bagian yang terpisahkan dari Quality Control/Quality Assurance proyek. 
Radiography test adalah salah satu pengujian yang tidak merusak, untuk mendiagnosa kualitas sambungan pipa-pipa ataupun material logam lainnya melalui penampakan bayangan dengan media berupa film, di bidang medis populer dengan istilah rontgent. Pada kilang minyak, kualitas sambungan pipa logam yang dilakukan penyambungan dengan las, wajib memenuhi standar internasional yaitu American Petroleum Institute dan American Society Mechanical Engineering. Transparansi dari sambungan las dapat dibaca pada rekaman radiography film. Film inilah yang akan dipergunakan sebagai obyek atau media untuk menginterpretasikan kualitas pengelasan.

Kualitas pengelasan dapat dikategorikan memenuhi standar jika hasil analisis pada radiography film dibaca tidak ada cacat atau defect tidak melebihi toleransi yang diijinkan. Jika hasil pengelasan tidak sesuai standar maka perlu dilakukan uji ulang (re-work). Untuk bisa dibaca dengan baik maka kualitas film hasil uji radiography harus memenuhi standar kualitas agar tidak terjadi kesalahan interpretasi.

Pengulangan atau rework dalam dunia industri adalah termasuk salah satu waste atau reject. Menurut Taichi Ono dalam, rework adalah termasuk salah satu dari 7 waste dalam konsep lean production yang harus diminimalkan ataupun dihilangkan [1]. Rework dalam istilah pengujian radiography disebut retake atau re-shoot, yaitu pekerjaan yang mengulangi pekerjaan yang sama untuk menghasilkan film dengan quality image yang standar. Rework/re-take/reshoot menjadi tidak ekonomis dipandang dari sudut biaya dan waktu pengerjaan. Dari sisi safety and health berpotensi tidak aman dan tidak sehat, karena pekerja radiography harus melakukan pengujian ulang, sehingga berpotensi terkena paparan radiasi. Secara akumulasi pekerja akan terpapar radiasi pada saat melakukan pekerjan pengulangan. Sehingga jika dikaitkan dengan kesehatan menjadi beresiko. Secara prinsip pengujian ini mempunyai dampak cukup berbahaya, karena paparan radiasi bersifat tidak terlihat dan tidak dapat dirasakan secara langsung pada saat itu.
Berdasarkan data PT. Sucofindo pada tahun 2015 hasil rekaman pengujian radiography test di kilang minyak Cilacap selama periode November 2013 sampai dengan Desember 2014, tingkat pengulangan pengujian (rework atau reshoot) cukup tinggi mencapai angka 8 persen. Dari 33.000 sheet yang dilakukan pengujian terdapat 2.666 sheet yang harus diulang (rework).

Penelitian terkait dengan kualitas film radiography yang mengakibatkan harus dilakukan rework/re-take/reshoot sudah banyak diteliti sebelumnya. Sebagian besar penelitian terkait analisis waste pada uji radiography dilakukan di dunia medis khususnya di rumah sakit. Tingkat pengulangan yang dilaporkan peneliti sangat bervariasi. Prosentase rework/retake/reshoot berdasarkan penelitian beberapa penelitian ter dahulu berkisar 8,1-9,9\%, berkisar 7,69-13,82\%, berkisar 10\%, berkisar 11,5\%, berkisar 3,2-11\%, berkisar 2-20\%, berkisar 10$15 \%$, berkisar $8,6 \%$, berkisar $4-35 \%$, dan berkisar 7,20\% [2][3][4][5][6][7].

Penyebab-penyebab yang dominan berasal under exposure dilaporkan 38\%, over expossure dilaporkan $54 \%$ dan positioning dilaporkan 18\%. Penyebab kondisi tersebut menurut peneliti sebelumnya akibat dari faktor manusia (human factor) dan lebih berhubungan dengan pengalaman kerja (working experience). Namun sebagian besar analisis tersebut berorientasi pada dunia medis. Peralatan pengujian yang digunakan dalam uji radiography di dunia medis menggunakan sinar$\mathrm{X}$, sementara pada pengelasan sambungan pipa di kilang minyak Cilacap menggunakan sumber sinar Gamma. Dengan demikian terdapat perbedaan terkait dengan sumber energi yang dipakai dan memungkinkan terjadinya perbedaan dari peyebab masalah.

Analisis minimisasi waste pada uji radiography di kilang minyak Cilacap ini dipandang perlu mengingat bahwa metode uji radiography ini diterapkan pada proyek pemerintah yang diharapkan dapat mendukung kebutuhan BBM secara nasional. Tujuan penelitian ini adalah mencoba menganalisis faktor-faktor yang menyebabkan tingginya waste berupa rework pada proyek pengelasan kilang minyak Cilacap dan merekomendasikan 
cara yang tepat untuk melakukan perbaikan (improvement) sehingga tingkat waste atau rework dapat diminimumkan dengan menggunakan metode DMAIC (DefineMeasure-Analysis-Improve-Control). Dengan harapan jika di kemudian hari ada proyek yang serupa, maka tingkat waste (rework/retake/reshoot) dapat diminimalkan sehingga para pekerjanya tidak terpapar radiasi dengan akumulasi yang tinggi pada periode waktu tertentu.

\section{METODE PENELITIAN}

Metode DMAIC (Define-MeasureAnalysis-Improve-Control) merupakan salah satu metode closed loop yang telah dipercaya dipakai dalam bidang industri maupun manufacturing untuk meningkatkan performance maupun untuk mengeliminasi waste hasil suatu kondisi unproductive process (non value added step). Secara general DMAIC dapat diimplementasikan sebagai prosedur peningkatan kualitas yang mandiri, metode DMAIC juga dapat digunakan untuk menangani permasalahan yang kompleks. DMAIC telah digunakan oleh banyak perusahaan tidak hanya untuk peningkatan kualitas dan perbaikan proses, namun juga telah diimplementasikan untuk bussiness planing dan problem solving. Tahapan DMAIC dan tools yang digunakan disajikan dalam Gambar 1.

Define adalah tahapan penentuan awal yang sangat menentukan keberhasilan suatu proyek, terutama dalam penentuan problem, goal, potential resources, project scope, project time line. Dengan direct observation semua data yang bersumber pada fakta dari pihak-pihak yang terkait secara obyektif dicatat. Selanjutnya dibuat grafik atau chart untuk memudahkan klasifikasi terhadap faktor-faktor yang menjadi konsentrasi penelitian.

Pada kasus ini masalah yang timbul adalah terjadinya suatu rework/re-take/reshoot pada uji radiography pengelasan kilang minyak Cilacap. Minimum langkah perlu dilakukan adalah identifikasi masalah utama yang timbul (Main Problem Occur), identifikasi pelanggan atau stakeholder, identifikasi proses yang kritis ataupun output yang kritis (Voice of Customer, Voice of Bussines \& Critical to Quality), menentukan sasaran yang dituju dan cara yang dipilih untuk mengatasi masalah-masalah utama (set the project goal/target goal, project scope and target process) menentukan aturan-aturan dasar, faktor-faktor yang akan diukur dalam rangka perbaikan (improvement), cara analisis

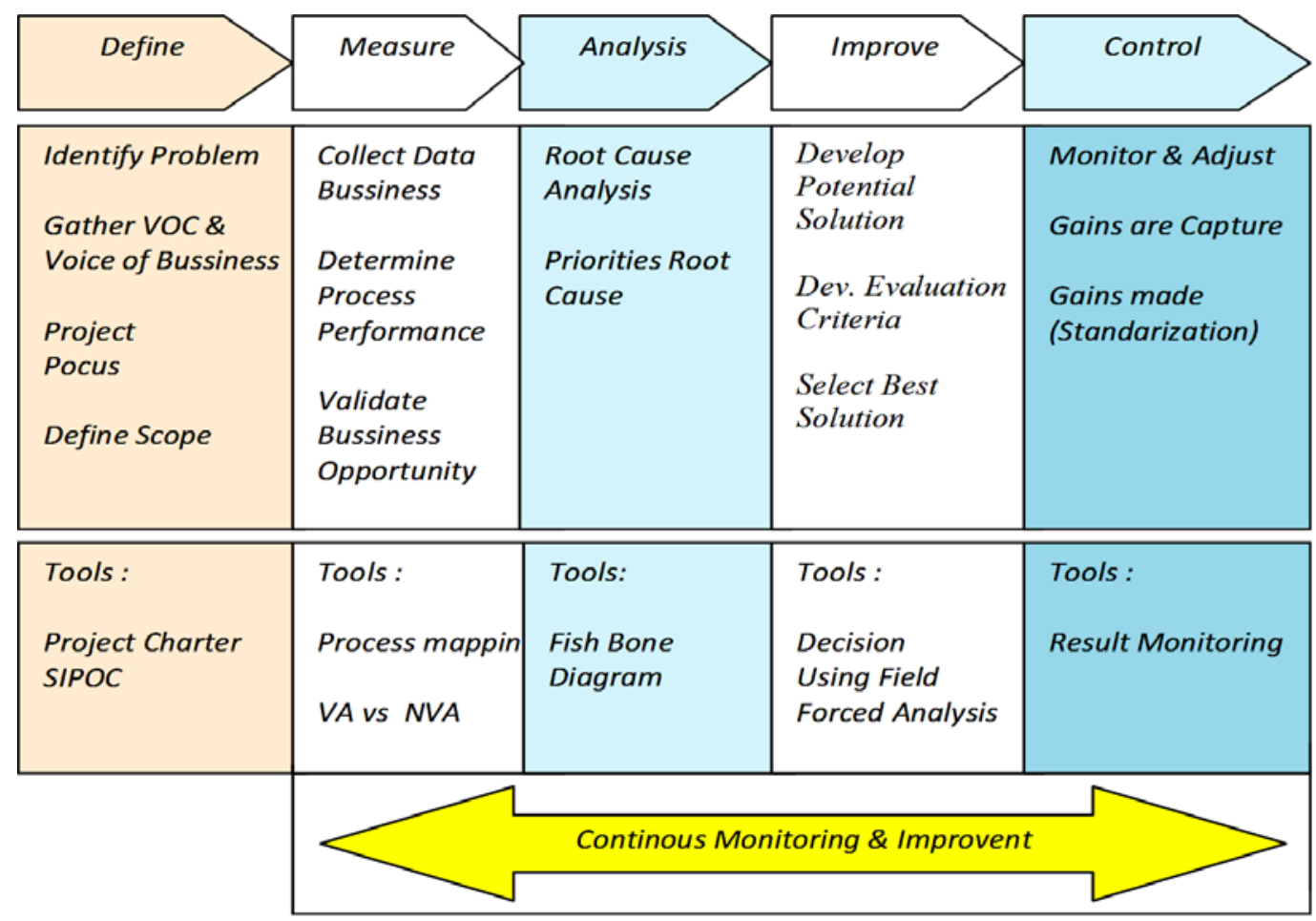

Gambar 1. Tahapan dan Tools yang Digunakan dalam Proses DMAIC 
dan pengendalian. Kunci sukses tahapan ini pihak manajemen menyetujui atas langkah menuju goal statement.

Measure adalah tahapan pengukuran atas obyek yang diteliti yang nantinya akan dilakukan perbaikan. Kinerja saat ini dibandingkan setelah dilakukan tindakan perbaikan. Langkah yang dilakukan adalah mengumpulkan data untuk membuat dan menetukan kinerja proses, menilai kesenjangan kinerja saat ini dengan yang diperlukan, menilai sistem pengukuran saat ini sudah sesuasi atau belum, dan membuat aliran proses mulai dari dasar sampai tingkat lanjut.

Permasalahan yang timbul harus dapat diukur. Pada tahapan ini fokus kepada proses pengukuran kinerja yang menjadi fokus untuk perbaikan dan mengumpulkan semua data yang diperlukan untuk analisis. Minimum tahapan yang harus dilakukan adalah membuat Process Flow Chart. Secara ideal dapat menggunakan "Proses Mapping" agar setiap proses terlihat dengan jelas dan detail, melakukan pengukuran secara kesisteman dan melakukan validasi dan menentukan performance saat ini sebagai base line performance.

Kunci sukses tahapan ini adalah tersedianya data sebagai baseline, pengukuran yang lazim untuk produk yang diteliti dan melibatkan tenaga ahli yang memahami produk dan proses ke dalam tim agar langkah yang akan dilakukan terarah.

Analysis yaitu tahapan verifikasi, identifikasi dan analisis atas faktor-faktor yang muncul. Sejumlah masalah yang muncul dilakukan analisis dan diselesaikan menggunakan fish bone diagram. Sebanyak 3-4 permasalahan utama dari seluruh permasalahan ditetapkan untuk dianalisis lebih lanjut. Beberapa langkah yang diperlukan adalah membuat daftar penyebab masalah yang potensial, menentukan secara prioritas penyebab masalah guna penentuan langkah perbaikan, mengidentifikasi bagaimana suatu proses input dapat mempengaruhi proses output dan membuat proses mapping secara detail untuk membantu mementukan di proses mana terjadi suatu masalah dan apa yang berkontribusi sehingga sesuatu masalah bisa terjadi.
Minimum langkah yang harus dilakukan adalah penyebab masalah yang utama (major) teridentifikasi dan dipahami secara bersama bahwa itu merupakan masalah, tersedianya data yang terukur untuk dilakukan analisis dan tools yang digunakan adalah fish bone diagram dan why-why analysis.

Improve yaitu tahapan perbaikan dimana permasalahan utama sudah teridentifikasi dari mapping proses. Improve adalah suatu langkah kreatif dalam pemilihan solusi untuk menyelesaikan masalah. Perbaikan perlu dilakukan atas bebeberapa masalah utama. Sasaran utama dalam tahap ini adalah solusi yang terbaik yang tepat dan dapat diimplementasikan sesuai kondisi saat ini. Ada beberapa langkah yang perlu dilakukan yaitu membuat Process Flow Chart, secara ideal dapat menggunakan "Proses Mapping" agar setiap proses terlihat dengan jelas dan detail, melakukan pengukuran secara kesisteman dan lakukan validasi dan menentukan performance saat ini sebagai base line performance.

Minimum langkah yang harus dilakukan adalah tim melakukan pengawasan terhadap masalah yang telah dijadikan sebagai prioritas utama menuju arah sasaran utamanya dan secara jelas hindari kesalah pahaman terkait dengan deifinisi dari permasalahan yang ada.

Kunci sukses tahapan ini adalah masalah utama yang sudah dipilah berdasarkan prioritas disetujui secara bersama. Analisis menggunakan fish bone diagram dan why-why analyis tidak boleh dilakukan secara tersendiri untuk menghindari opini yang individual.

Tools yang digunakan adalah Forced Field Analysis (FFA). Kunci sukses FFA adalah kajian antara Forced to Change dan Forced Againt Change realistis dapat diterima berdasarkan penilaian dari tim dan keputusan bersama, dengan mempertimbangkan masukan dari tenaga ahli yang dilibatkan. Usulan dapat diterima oleh manajemen dan tidak menimbulkan dampak yang berarti.

Control adalah tahapan melakukan pemantauan terhadap solusi yang sudah disepakati sebagai alternatif. Beberapa tekanan (Forces) sering muncul pada saat adanya suatu perubahan. Terkadang tekanan ini yang menjadikan penghambat untuk tercapainya 


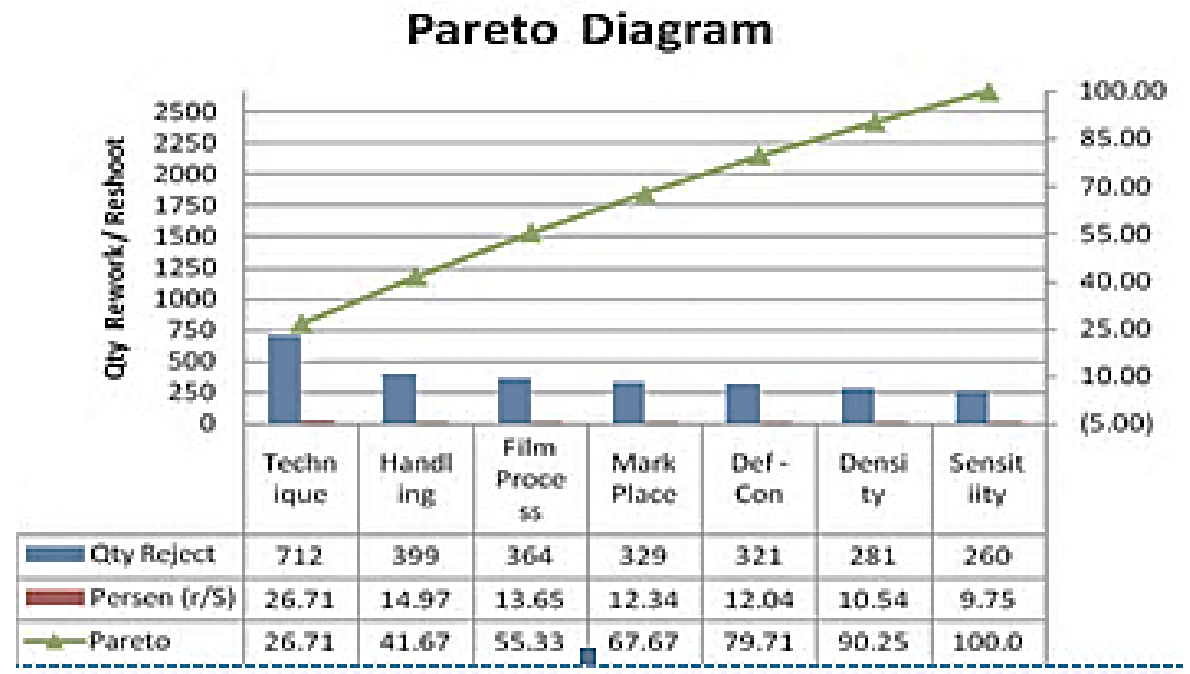

Gambar 2. Pareto Diagram Reject pada Uji Radiography
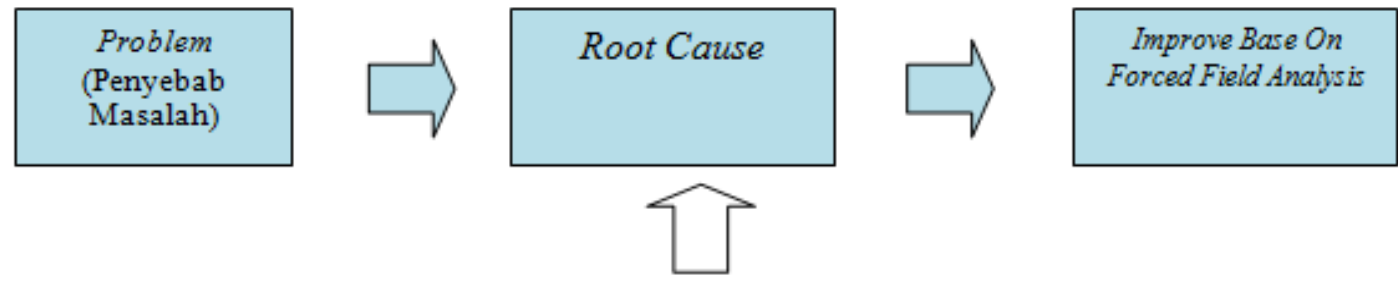

Fish Bone

WHY-WHY

Gambar 3. Proses Analisis Masalah Minimisasi Waste Atau Rework Uji Radiography

sasaran. Metode baru dalam rangka perbaikan dimasukkan ke dalam revisi langkah kerja sebagai Standard Operating Procedure yang baru dan disosialisasikan agar seluruh pihak memahami.

Kunci sukses tahapan ini adalah jika harus dibuat rencana control maka harus dilakukan audit terhadap pelaksanaan controlnya agar dapat dipastikan semua berjalan sesuai rencana.

\section{HASIL DAN PEMBAHASAN}

Diagram Pareto yang menunjukkan data reject hasil pengujian radiography disajikan pada Gambar 2. Faktor penyebab kegagalan utama berasal dari faktor technique mendekati angka 27\%, disusul handling sekitar 15\%, dan film processing sekitar $14 \%$. Sehubungan dengan target yang ditetapkan oleh perusahaan $4 \%$ reject yang berarti turun $50 \%$ dari kondisi existing, maka perlu dilakukan perbaikan dari ke tiga faktor di atas. Jika hanya faktor yang tertinggi saja yang dilakukan perbaikan, maka target reject keseluruhan tidak tercapai. Untuk itu perlu dilakukan perbaikan pada ketiga faktor penyebab tersebut, dengan begitu diharapkan prosentase reject dapat turun mencapai 55,33\%, atau reject bisa mencapai 3,6\%.

Sesuai dengan urutan prioritas, maka ketiga faktor penyebab masalah tersebut dianalisis menggunakan fishbone diagram dan dilanjutkan dengan why-why analysis dan dilakukan perbaikan dengan forced field analysis seperti diilustrasikan pada Gambar 3.

\section{Prioritas 1 Masalah Technique}

Faktor Technique jika diidentifikasi dengan SIPOC diagram seperti terlihat dalam Gambar 4, maka terjadinya sebelum film Pack diserahkan kepada dark room man, exposure film (film yang sudah di-shoot/film yang sudah disinari radiasi) untuk dilakukan processing film. Jika diidentifikasi dengan proses mapping, maka dapat terlihat pada sajian Gambar 4. 


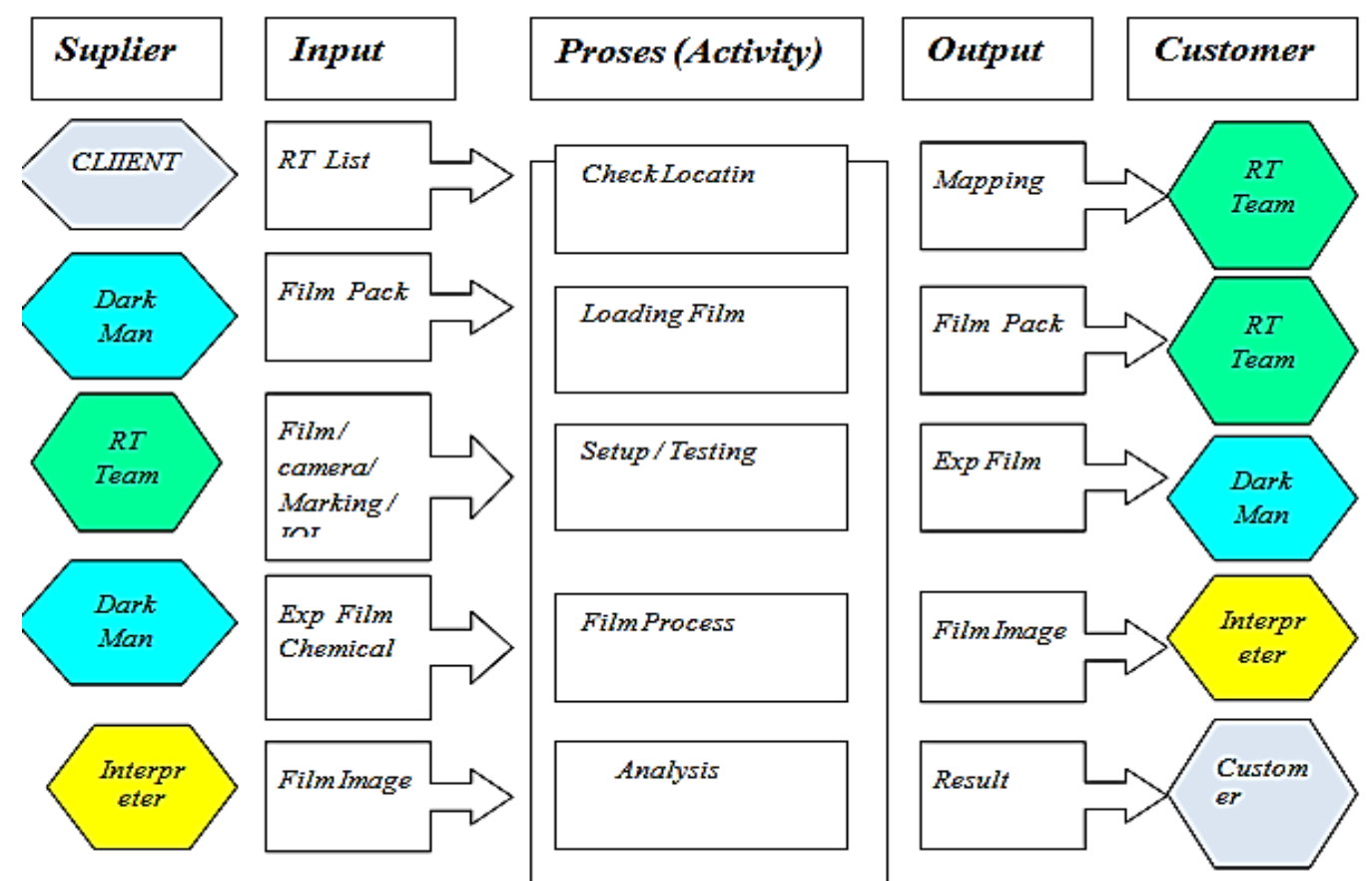

Gambar 4. SIPOC Diagram Uji Radiography

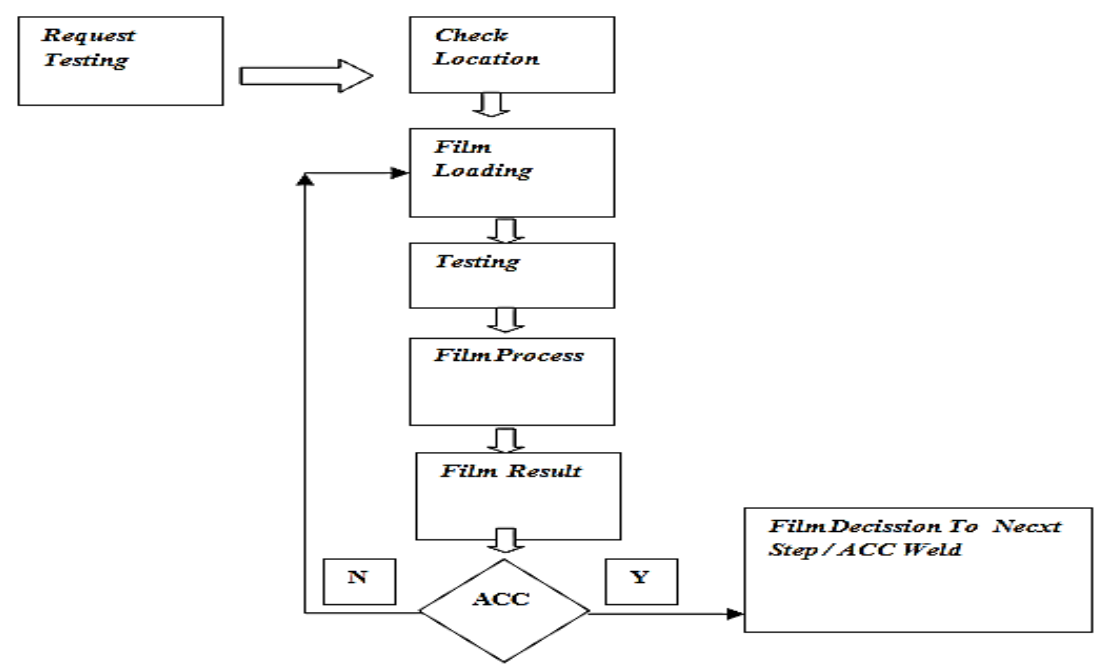

Gambar 5. Proses Mapping Uji Radiography

Dilihat dari Project Charter, maka unsur man, machine, material, method, environment turut berpotensi menjadi penyebab. Selanjutnya efek dari masing-masing akibat yang ditimbulkan (effect) dielaborasi untuk mendapatkan akar masalah.

Analisis fishbone diagram untuk faktor technique dilakukan melalui brainstorming bersama tim, melibatkan pekerja Radiography dengan pertanyaan "Kenapa hal ini terjadi" untuk menjawab peyebab dari masing-masing cabang. Ringkasannya dijabarkan pada Gambar 6 dan Tabel 1.
Selanjutnya dilakukan analisis why-why untuk menggali lebih dalam atas permasalahan tersebut hingga ditemukan penyebab yang sistematis. Pertanyaan yang muncul dapat terlihat dalam Gambar 7.

\section{Prioritas 2 Masalah Handling}

Dengan mengulang cara yang sama seperti pada prioritas sebelumnya, dilakukan analisis penyebab terhadap masalah handling pada Tabel 2 dan Gambar 8 kemudian dilanjutkan dengan why-why analysis pada Gambar 9. 


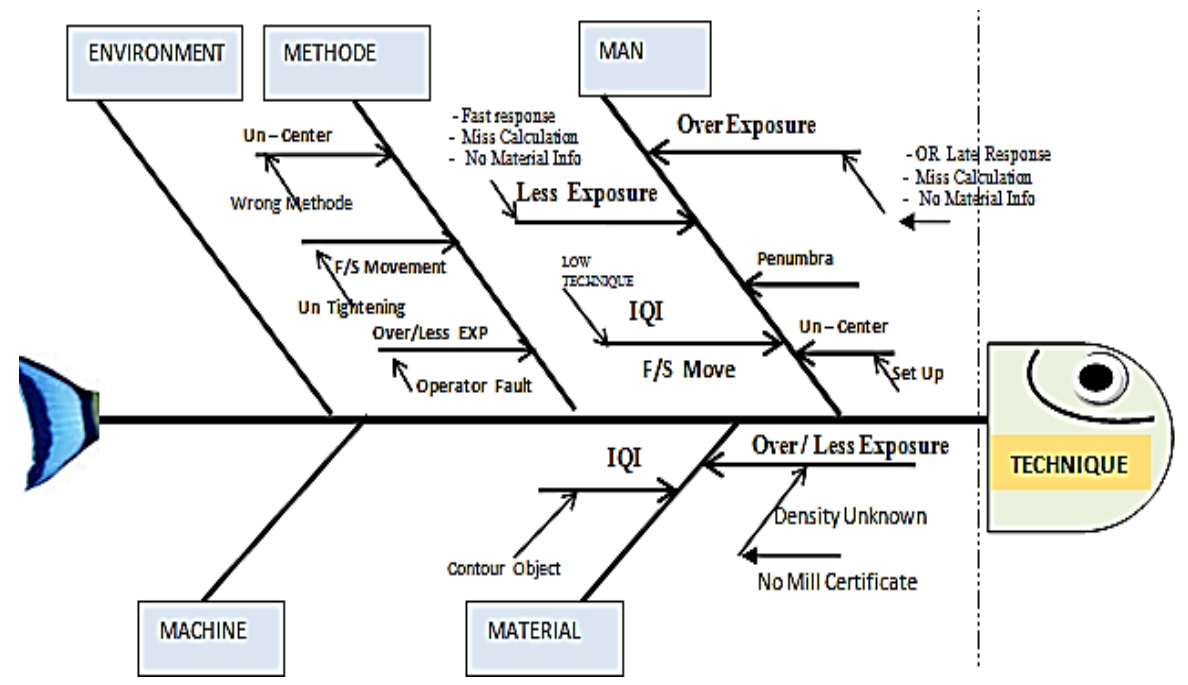

Gambar 6. Analisis Fishbone Diagram Faktor Technique

Tabel 1. Penyebab dari Technique

\begin{tabular}{lccccc}
\hline \multicolumn{1}{c}{ Indicator Rework } & Man & Machine & Material & Methode & Env \\
\hline Over Exposure & ++ & ++ & 0 & 0 & ++ \\
Less Exposure & ++ & ++ & 0 & 0 & ++ \\
Penumbra & ++ & ++ & ++ & 0 & ++ \\
IQI Place Placement & ++ & ++ & 0 & ++ & ++ \\
F/S Movement & ++ & ++ & ++ & 0 & ++ \\
Un-Centre Viewing & ++ & ++ & 0 & 0 & ++ \\
\hline \multicolumn{4}{c}{ Keterangan ++} \\
yes/penyebab & $0=$ no/bukan sebagai penyebab
\end{tabular}

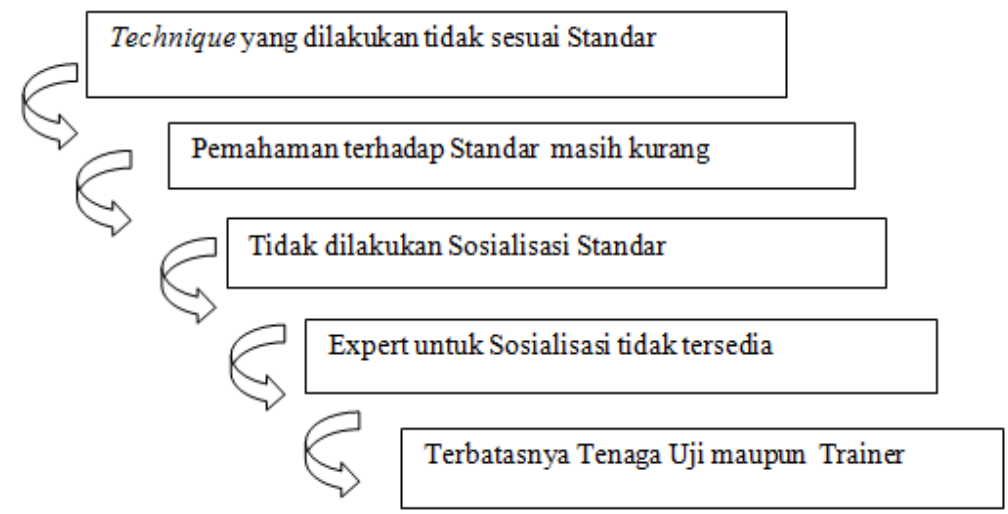

Gambar 7. Analisis Why-Why Faktor Technique

Tabel 2. Penyebab dari Faktor Handling

\begin{tabular}{lccccc}
\hline \multicolumn{1}{c}{ Indicator Rework } & Man & Machine & Material & Methode & Env \\
\hline Scratch & ++ & 0 & ++ & ++ & 0 \\
Nail Mark & ++ & 0 & ++ & ++ & 0 \\
Water Mark & ++ & 0 & ++ & ++ & 0 \\
Darkness & ++ & 0 & ++ & ++ & 0 \\
\hline
\end{tabular}

Keterangan $++=$ yes/penyebab $0=$ no/bukan sebagai penyebab

\section{Prioritas 3 Masalah Film Processing}

Dari ketiga prioritas masalah di atas telah teridentifikasi penyebab dan akar masalahnya, selanjutnya dilakukan perbaikan untuk permasalahan tersebut. Untuk mencari solusi terbaik dan tepat bagi permasalahan tersebut digunakan forced field analysis (FFA). FFA adalah sebuah tools yang digunakan untuk menganalisis faktor-faktor permasalahan yang kompleks seperti experienced, resources, 


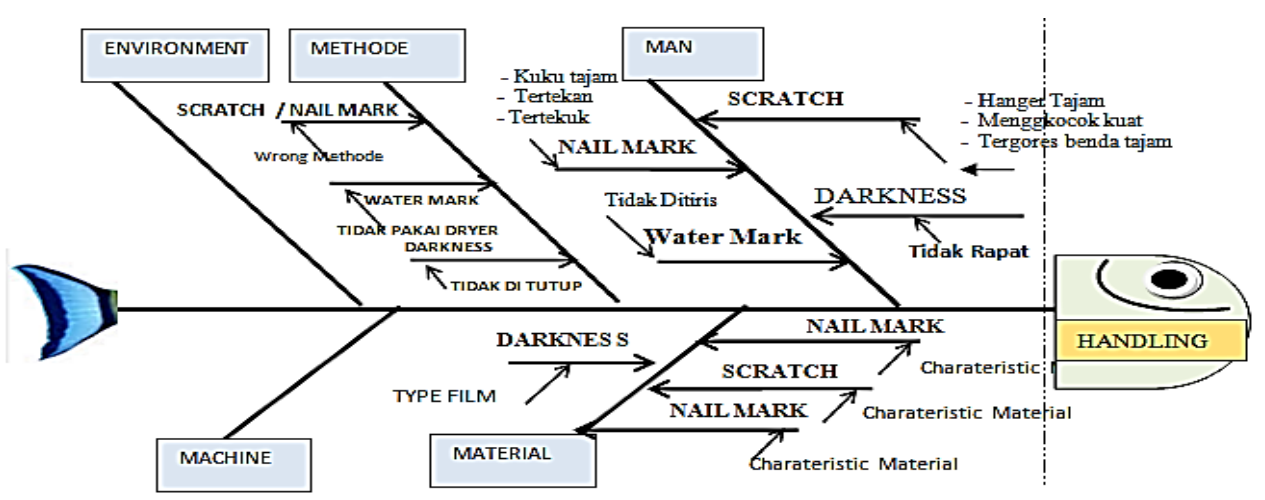

Gambar 8. Analisis Fishbone Diagram Faktor Handling

Handling tidak dilakukan dengan Baik

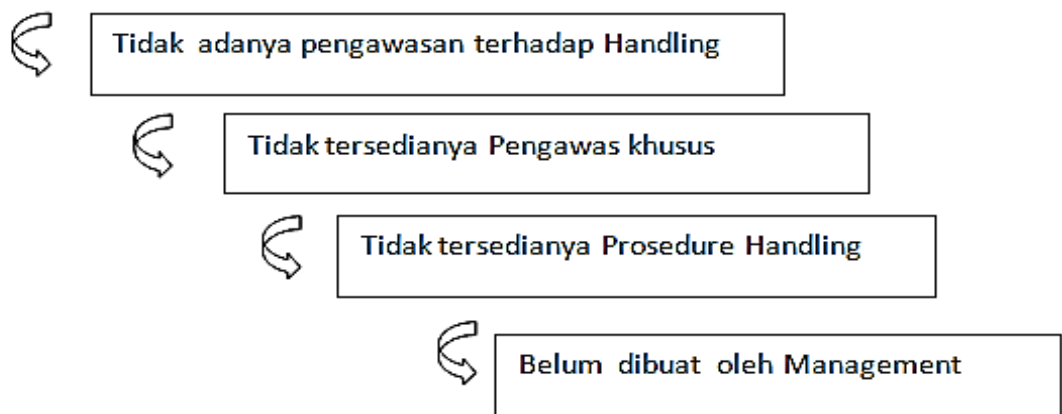

Gambar 9. Analisis Why-Why Faktor Handling

Tabel 3. Penyebab dari Film Processing

\begin{tabular}{lccccc}
\hline \multicolumn{1}{c}{ Indicator Rework } & Man & Machine & Material & Methode & Env \\
\hline Uncleat & 0 & 0 & ++ & ++ & 0 \\
Storage Scrath & ++ & 0 & ++ & ++ & 0 \\
Safe Light & 0 & ++ & 0 & ++ & 0 \\
Spot Fix & ++ & 0 & 0 & 0 & 0 \\
Spot Dev & ++ & 0 & 0 & ++ & 0 \\
Foggy & 0 & 0 & 0 & ++ & ++ \\
\hline
\end{tabular}

attitude, tradition. FFA diharapkan dapat mendukung dalam memgambil langkah-langkah perbaikan atau perubahan (change) yang akan dilakukan secara masif. Setiap change tentu ada resistansi. Dengan FFA akan lebih mudah mengidentifikasi hambatan ataupun memprediksi tingkat effort yang diperlukan untuk mencapai sasaran.

Kolom sebelah kiri pada FFA pada Gambar 11 adalah yang mendorong suatu perubahan harus dilakukan untuk sasaran tertentu. Sedangkan kolom sebelah kanan adalah kolom yang terdiri dari langkah-langkah yang akan dilakukan dalam rangka mencapai sasaran. Dalam menuju ke sesuatu sasaran tentunya ada biaya, waktu dan kondisi-kondisi lainnya sebagai penghambat. Seberapa besar hambatan dan tenaga yang dibutuhkan diberi skor penilaian untuk memprediksi tingat kesulitan dalam mencapai sasaran. Kolom kanan disebut sebagai Forced Againts Change. Hasil penilaian kondisi awal dihasilkan skor 10 dan kondisi ke depan skor 18. Maknanya adalah diharapkan situasinya akan meningkat 8 point, namun juga memerlukan tenaga yang cukup besar untuk mencapainya.

Tahapan setelah dilakukan improvement mengacu kepada FAC (Forced Againts Change) diamati apakah usulan perbaikan tersebut jika dimasukkan ke dalam sistem akan dapat diterapkan dan bisa berjalan stabil. Untuk itu perlu dilakukan kontrol dan monitoring atas 


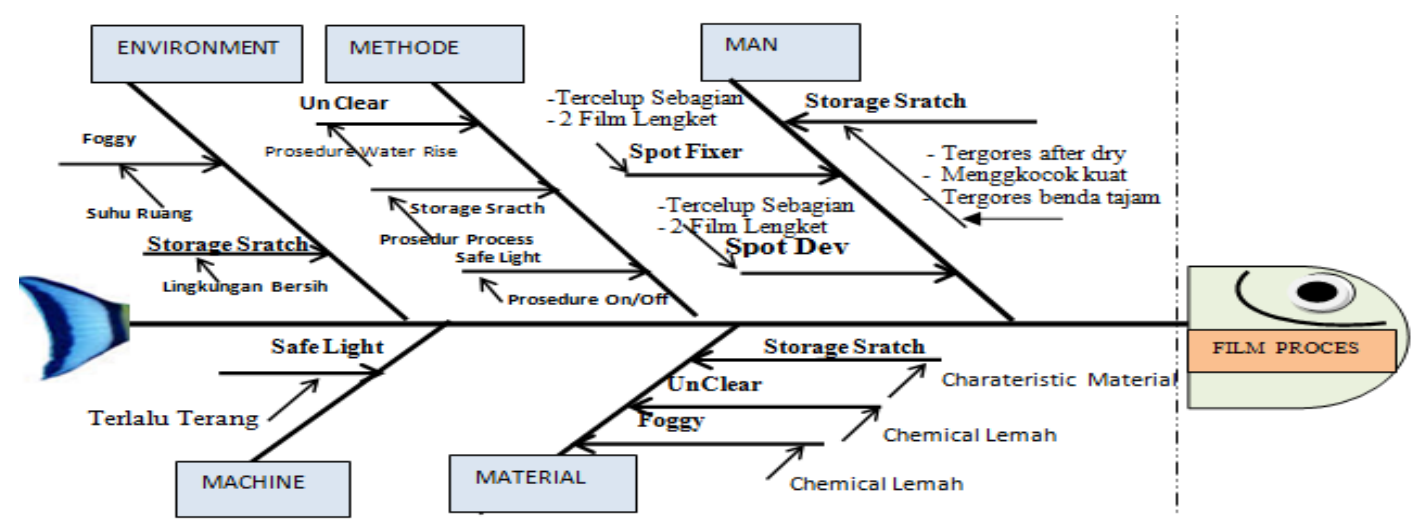

Gambar 10. Fishbone-Handling

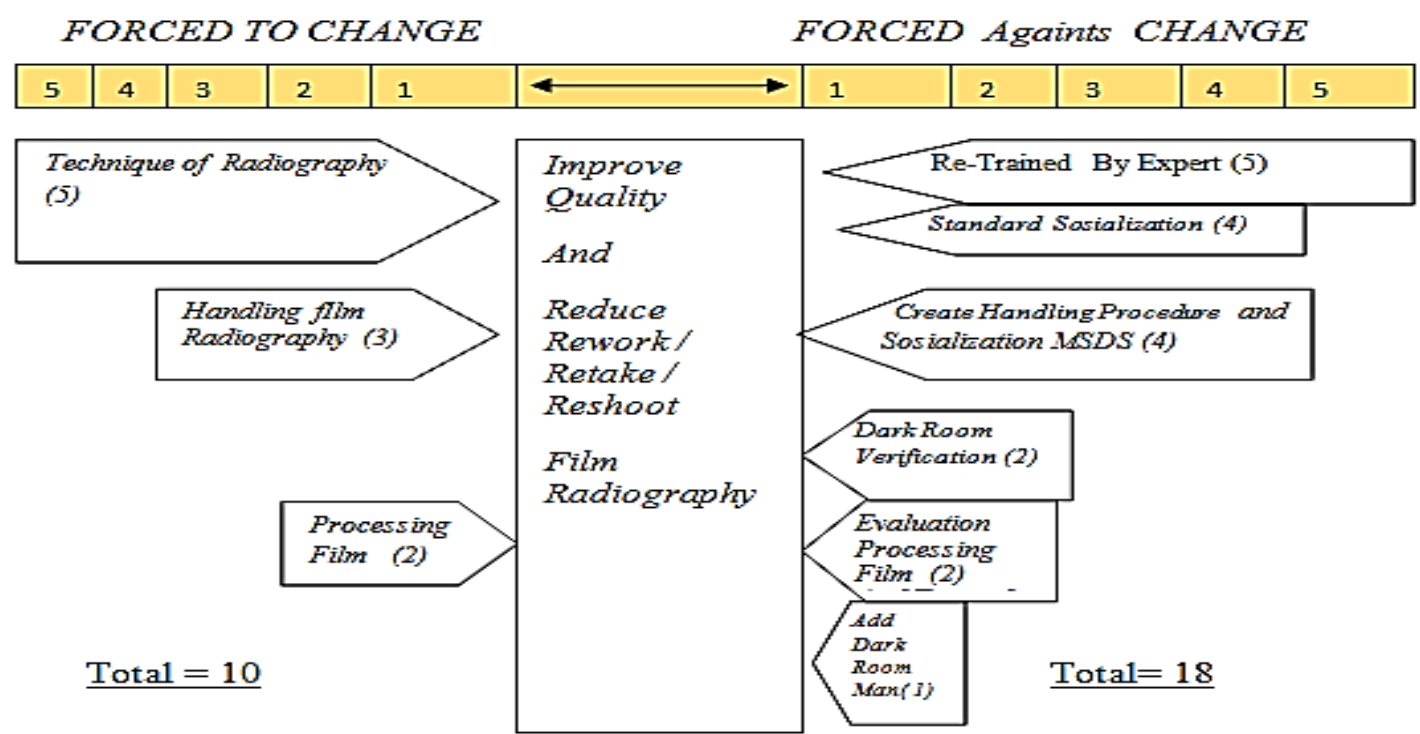

Weak =1;2 Weak Medium ; Medium=3; 4=Medium-Strong Strong = 5 Gambar Gambar 11. Forced Field Analysis

hal-hal yang sudah dilakukan. Setelah dilakulan langkah-langkah sesuai FFA melalui ujicoba selama 3 bulan dihasilkan improvement seperti pada Tabel 4. Tingkat waste atau rework ratarata pada tahap awal sebesar $8 \%$ berhasil diturunkan menjadi 4,21\%. Proses improvement berikutnya dapat diprioritaskan pada faktor sensitivity, def-con, dan technique.

Tabel 4. Setelah Improvement April-Juni 2015

\begin{tabular}{clllll}
\hline \multicolumn{1}{c}{ Bulan } & Apr & Mei & Jun & Total & $\%$ \\
\hline Jumlah Shoot & 350 & 400 & 532 & 1282 & 100 \\
Total Reject & 18 & 17 & 19 & 54 & 4,21 \\
\hline
\end{tabular}

Faktor Technique mendominiasi terjadinya rework pada uji radiography pengelasan kilang minyak Cilacap. Akibat dari faktor ini film radiography menjadi tidak terbaca atau film tidak layak untuk dijadikan sebagai acuan untuk mendiagnosa kualitas oyek yang sedang diuji. Berdasarkan Standard ASME SEC $V$ Edition 2010 yang tergolong faktor technique berasal dari indicator over exposure, less exposure, penumbra, iqi placement, film/source movement, atau un center viewing. Faktor ini lebih banyak dipengaruhi oleh man, machine dan environment. Yang berhubungan dengan man dalam pengujian ini terkait dengan pemahaman atas standard yang dipakai dan tatacara (procedure) dalam melakukan pengujian, sedangkan yang berkaitan dengan machine terkait berfungsinya sistem dari peralatan tersebut. Faktor environment lebih banyak dipengaruhi oleh kondisi di lapangan yang bervariasi. 
Tabel 5. Jenis Reject Setelah Improvement April-Juni 2015

\begin{tabular}{lccccr}
\hline \multicolumn{1}{c}{ Bulan } & Apr & Mei & Jun & Total & \multicolumn{1}{c}{$\%$} \\
\hline Sensitivity & 3 & 3 & 3 & 9 & 16,67 \\
Density & 4 & 2 & 2 & 8 & 14,81 \\
Def-Con & 3 & 3 & 3 & 9 & 16,67 \\
Mark Place & 2 & 2 & 3 & 7 & 12,96 \\
Handling & 1 & 2 & 2 & 5 & 9,26 \\
Film Process & 2 & 2 & 3 & 7 & 12,96 \\
Technique & 3 & 3 & 3 & 9 & 16,67 \\
\hline
\end{tabular}

Faktor Handling mendominasi urutan kedua dari permasalahan rework uji radiography pengelasan kilang minyak Cilacap. Akibat yang ditimbulkan dari faktor ini, terkadang film masih dapat dilakukan untuk mendiagnosa terhadap obyek yang diuji. Namun karena faktor Aesthetic yang ada dalam salah satu dimensi kualitas. Faktor ini menjadikan penyebab sehingga Film harus dilakukan Rework. Faktor-faktor yang termasuk dalam kelompok ini antara lain adalah sracth, water mark, darkness/bocor, atau nail mark (bekas kuku). Faktor-faktor ini lebih banyak ditimbulkan akibat gerakan (motion) yang dilakukan oleh para pekerja (man). Disamping sifat karaterisik dari material film yang terbuat dari gelatin bersifat resisten terhadap benturan ataupun tekanan benda-benda yang tumpul maupun tajam yang dapat mengakibatkan film radiography luka (dent)

Faktor Film Processing adalah faktor kunci dalam rangkaian pengujian. Meskipun technique yang digunakan sudah sesuai dan cara handling juga sudah mengacu pada kehatihatian, namun dalam processing film dapat menyebabkan terjadinya kegagalan kualitas. Yang menjadi penyebab kelompok ini antar lain adalah unclear, storage scratch, safelight, spot fixing/over fixing, spot developing/over developing, atau foggy. Faktor-faktor yang mempunyai kontribusi terhadap timbulnya permasalahan dalam proses film lebih banyak ditimbulkan dari efek material, yaitu chemical yang digunakan. Chemical mempunyai limitasi daya proses. Efek machine atau peralatan pendukung seperti hanger juga dapat menyebabkan tergoresnya film pada saat proses developing. Efek lainnya yang menyebabkan timbulnya rework adalah faktor environment, seperti suhu ruang harus $<20^{\circ} \mathrm{C}$. Faktor man juga mempunyai kontribusi pada saat processing. Dark room man memerlukan tingkat pengalaman yang tinggi. Dark room man harus terbiasa bekerja di ruang gelap, hanya dibantu oleh red lamp sebagai penerangan.

Jika dibandingkan dengan penelitian sebelumnya yang kebanyakan pada bidang medis, kondisi awal reject ditemukan di kisaran 7-13\%, bahkan ada yang lebih besar mencapai angka 33\%. Proses improvement berhasil menurunkan waste atau reject film radiography menjadi $10-4,5 \%$. Pada penelitian ini persentase reject film radiography pengelasan berhasil diturunkan mencapai angka 4,21\% atau lebih baik $0,29 \%$ dibandingkan penelitian sebelumnya.

Ada beberapa kelemahan dari penelitian ini, jika dilihat dari durasi pengamatan setelah dilakukan perbaikan. Pada penelitian ini proses improvement baru diimplementasikan selama 3 bulan. Analisis tingkat waste atau reject pada tahap awal berasal dari hasil uji selama 15 bulan dengan total film 33.000 sheet, sedangkan analisis improvement dalam penelitian dihasilkan dari sample yang berjumlah sekitar 1282 sheet.

\section{KESIMPULAN}

Tiga faktor penyebab utama tingginya tingkat waste atau rework/re-take/reshoot pada uji radiography hasil pengelasan kilang minyak Cilacap adalah faktor teknik, handling, dan processing dengan total kontribusi 51\% terhadap permasalahan. Akar penyebab masalah untuk faktor teknik terkait dengan kurangnya pemahaman terhadap standard dan terbatasnya tenaga ahli terkait di Indonesia. Masalah handling timbul akibat belum tersedianya prosedur handling serta tidak dilakukannya kontrol pada proses handling. Sementara masalah processing disebabkan oleh terbatasnya informasi material data sheet dan tidak tersedianya label durasi shoot.

Berdasarkan hasil penelitian dapat direkomendasikan hal-hal berikut kepada tim radiography pengelasan kilang minyak Cilacap melakukan analisis singkat bersama tim sebelum pengujian, meningkatkan pemahaman terhadap standar pengujian, pemahaman 
material yang akan diuji lebih mendalam, menambah pengetahuan pembacaan gambar proyek (drawing), mengkalkulasi waktu shoot tidak sendiri, konsentrasi tinggi dan focus pada saat pengujian dan pemprosesan, melakukan handling peralatan dan bahan dengan hati-hati, sharing informasi antara tim teknis dan tim prosesing, mengetahui proses secara general kilang minyak, dan memastikan daerah aman terhadap potensi bahaya radiasi.

\section{DAFTAR PUSTAKA}

[1] Liker, J. K., \& Morgan, J. M. (2006). The Toyota way in services: the case of lean product development. The Academy of Management Perspectives, 20(2), 5-20.

[2] Al-Malki, M. A., Abulfaraj, W. H., Bhuiyan, S. I., \& Kinsara, A. A. (2003). A Study on Radiographic Repeat Rate Data of Several Hospitals in Jeddah. Radiation Protection Dosimetry 103(4): 323-330.

[3] Monfared, A. S., Abdi, R., \& Saber, M. A. (2007). Repeat analysis program in radiology departments in Mazandaran province-Iran; Impact on population radiation dose. Iran J Radiat Res, 5(1), 237-40.
[4] Akhtar, W., Aslam, M., Ali, A., Mirza, K., \& Ahmad, N. (2008). Film retakes in digital and conventional radiography. Journal of the College of Physicians and Surgeons Pakistan 18(3): 151-153

[5] Foos, D. H., Sehnert, W. J., Reiner, B., Siegel, E. L., Segal, A., \& Waldman, D. L. (2009). Digital radiography rejects analysis: data collection methodology, results, and recommendations from an indepth investigation at two hospitals. Journal of digital imaging 22(1): 89-98.

[6] Akintomide, A. O., Egbe, N. O., Bassey, D. E., Eduwem, D. U., \& Oyama, E. A. (2011). Journal of Association of Radiographers of Nigeria.

[7] Jabbari, N., Zeinali, A., \& Rahmatnezhad, L. (2012). Patient dose from radiographic rejects/repeats in radiology centers of Urmia University of Medical Sciences, Iran. Health 4(02): 94. 